\title{
EDUCATIONAL STRATEGIES USED TO IMPROVE ETHICS AND INTEGRITY IN ROMANIAN SPORT
}

\author{
Monica Stănescu, Rareș Stănescu \\ National University of Physical Education and Sport from Bucharest \\ ROMANIA \\ Email: 1monica_iulia@yahoo.com,2raresuniv@yahoo.com
}

\begin{abstract}
The issue of education in connection with ethics and integrity in sport is increasingly often coming to the attention of the education authorities and organizations, in the wake of the frequent irregularities identified at different levels of sport. From grassroots level to the professional sports level, a whole range of statistics on misbehavior demonstrate the increased frequency of violations in terms of sport specific regulations and rules. This paper presents educational strategies designed and implemented in Romania by various sport organizations that have stepped up, in the last few years, the educational measures aimed at preventing irregularities in sport, by implementing educational campaigns, courses, workshops, organizing exchanges of experience and promoting examples of good practice. There are also mentioned some Erasmus Plus Sport projects implemented by the National University of Physical Education and Sport, Bucharest, as a partner of international consortium devoted to the above-mentioned topic.
\end{abstract}

Keywords: clean sport; education; sport organization;

\section{INTRODUCTION}

The issue of ethics and integrity in sport remains in the attention of specialists as a result of the escalating phenomenon of violation of sport regulations. From the role-model status that sportsmen have among the general public they become defamed and criticized for a series of behaviors that are not in line with the spirit of sport, such as doping, violence, involvement in fixed matches. Equally, sport officials are accused of bad governance, money laundering and illegal betting.

For the past 40 years, the Council of Europe has advocated the promotion of the values of sport and its defence against threats at international, national and local level. The Anti-Doping Convention (ETS No.135, Strasbourg 16.11.1989), the European Convention on Spectator Violence and Misbehaviour at Sports Events and in particular at Football Matches (ETS No.120, Strasbourg, 19.08.1985) and the Convention on the Manipulation of Sports Competitions (Treaty No.215, Magglingen, 18.09.2014), Code of Sports Ethics (1992), are such statements.

In 2013, the Berlin Declaration of the European ministers responsible for Physical Education and Sports addressed the issue of integrity in sport and highlighted the need to defend the values of sport against fake matches, illegal betting, doping and corruption. (MINEPS, 2013) In the field of international sport, the most striking irregularities are those related to the consumption of prohibited substances and illegal bets (about 2-3 trillion US dollars annually, in various sports) (Cleret, McNamee \& Page, 2015). 
Consequently, more and more organizations - starting with the International Olympic Committees and international sports organizations - are actively involved in promoting clean sports.The International Olympic Committee was the first organization to set up an independent Ethics Committee, in 1999, to defend the ethical principles of the Olympic Movement.

These principles were subsequently brought together in the Code of Ethics. Jacque Rogge, the former chairman of the International Olympic Committee (IOC), noted the extent of the match-fixing and illegal betting phenomenon and how these examples of violation of sport ethics affect sport competitions. The most affected sports are football, basketball, cricket, horse racing, snooker, sumo, and tennis (Carpanter, 2012).

Starting in 2013, International Centre for Sport Security and the United Nations Office on Drugs and Crime have begun building an international platform to join government institutions, the sports movement, the sports betting industry, to act transnationally against these phenomena. Although such an approach is still far from being able to achieve its objectives, institutions with specific attributions in the fight against organized crime (Interpol, Europol) have participated in numerous actions that have resulted in the exposure of criminal networks in sport.

Along with previous mentioned steps to address irregularities, the sport organizations provide educational tools meant to give the support they need for their involvement in the fight for clean sports (Grigore, Stanescu \& Stoicescu, 2018).

In addition to the fact that the world of sports is encouraged to report violations of sports ethics and integrity, representative organizations have started educational programs to tackle them, education being one of the most valuable resources to prevent the abuse in sports ethics.

Among the first ones are IOC and FIFA, which run a series of educational awareness programs on out-of-law practices and have adopted internal rules on sanctioning athletes and officials involved in illegal actions.

World Anti-Doping Agency (WADA) was also one of the first international sporting bodies to introduce seminars and workshops to prevent match fixing, in 2007. In the same spirit, SportAccord encouraged international sports federations to initiate educational programs to prevent match fixing, illegal sports betting, and other crimes.

The design of these programs (face-to-face or on-line) included various informal tests that were meant to identify the level of assimilation of knowledge about the participant. The conclusions of the implementation of these programs were that only the multi-level strategies in the education of sports actors - athletes, coaches, parents and club managers - lead to longterm changes and increased efficiency.

\section{AIM OF THE PAPER}

Starting from a series of educational measures implemented at international level, this paper aims to present the position of our country in relation to these measures, and the educational strategies used in Romania in the field of education for ethics and integrity in sport.

\section{EDUCATION FOR ETHICS AND INTEGRITY IN ROMANIAN SPORTS}

In this light, educational programs should take into account the particularities of sporting groups and sports specialists, in each country and aims to develop skills to recognize 
irregularities or raising awareness of reporting possibilities that can increase the responsibility of individuals to adopt a misconducted behavior.

Romania signed the Antidoping Convention (135/1989), Additional Protocol to the Anti-Doping Convention (188/2002), European Convention on Spectator Violence and Misbehavior at Sports Events and in particular at Football Matches (120/1985). These programmatic documents are those that - included into the national strategy - generate the most numerous and more impactful events. Romania has yet to sign the Council of Europe Convention on the Manipulation of Sports Competitions (Treaty 215/2014).

\section{Anti-doping education}

The most active institution in the field of education for ethics and integrity is the National Anti-Doping Agency (NADA), which in the National Anti-Doping Strategy (20182022) makes distinct references to the Education Program and starts from the premise that it is easier to prevent than to eliminate a problem. The fundamental principle of this program is to preserve the sporting spirit by discouraging athletes from using prohibited substances and / or methods. The program comprises information and education projects for athletes and their entourage, in order to make them aware of the prohibited substances and methods, their effects on the body and the sport performance, the doping control procedures, the rights and responsibilities of the athletes. This educational program also aims to raise public awareness regarding the important aspects of anti-doping issues.

Using face-to-face and on-line programs, the agency offers anti-doping education programs for athletes and coaches from national teams, and a vocational training course for the Doping Control Officer. The anti-doping education program is mandatory for at least one employee of the private fitness clubs. The National Anti-Doping Agency must authorize the activity of bodybuilding or fitness halls, issuing an operation certificate in terms of antidoping regulations. These programs have been designed because in Romania, over the last 15 years, prohibited substances and methods were used by athletes and bodybuilders alike, those who are exercising in bodybuilding / fitness rooms. This situation represents a threat to the public health and the essential principles of sport and Olympism.

In collaboration with the Romanian College of Physicians, the agency also offers antidoping education for coaches, athletes and other specialists from interdisciplinary teams. Its aim is to increase inter-institutional collaboration in the development and implementation of informative and educational programs for the prevention and fight against doping in sport.

\section{Education for sport integrity}

In the case of doping, educational measures have been implemented gradually, while Romania adhered to the documents of the Council of Europe. However, from other perspectives of the fight against corruption in sport, the situation is different. Thus, although Romania is not a signatory to the Convention on the Manipulation of Sports Competitions (Treaty 215/2014), there are now numerous events on this topic.

One example of education for sport integrity is the "Integrity in Sport Seminar", as part of a Global Program for Training and Stimulating Sports Capabilities and Sport Staff, promoted by NOC and INTERPOL around the world, to help them avoid any new mistakes, which may be criminal, generated by the manipulation of competition results and other threats to the integrity of sport, and, at the same time, to encourage them to cooperate with police authorities in reporting and investigating such cases. This is an informal training program, not leading to professional qualification and/or accreditation.

Usually it is organized in countries around the world to encourage collaboration between local police, national Olympic committees and national sports federations, public 
authorities (including the Ministry of Justice, Ministry of Education and Sport, etc.), betting and other factors involved in preventing the infiltration of crime in sport, especially with regard to manipulation of competitions. In Romania this course was organized by the Romanian Olympic and Sports Committee (ROSC).

\section{Education for sport ethics}

Erasmus Plus Sport projects in Romania are constantly conducting a series of actions aimed at raising the awareness of the specialists in the field and the general public about the risks represented by misconducting behavior in sport and their consequences on the whole sports phenomenon. Projects such as Whistleblowing on Harmful Irregularities in Sport through Learning and Education (2016-3291/001-001), Development of a Course to teach Coaches Sport Integrity (2017-3344/001-001), Game Approach in Mitigating performance Enhancement culture in Youth (2017-3345/001-001), Not only fair play (2014-IT-SPO-SC) promote a host of sporting, scientific and cultural events, all under the tutelage of Ethics and Integrity in Sport.

In the field of non-formal education, many projects develop training courses for various categories of sport specialists. Here, we can include the courses offered by UNEFS: Sport Whistle and Course for Ethics and Integrity in Sport, within the Erasmus Plus Sport projects, where the university is a partner (Grigore, Stanescu \& Stoicescu, 2018).

A significant contribution to ethics education is provided by warning platforms. In Romania, there is the platform of the National Anti-Doping Agency, and another one managed by the Romanian Football Federation. Although there is no official data on the effectiveness of these platforms in tackling irregularities in sport, their existence marks a new approach to education for the recognition and reporting of irregularities.

Another relevant perspective on education for ethics in sport is the university curriculum, intended to train future coaches. It provides a course on Ethics and Deontology in Physical Education and Sports, where the main topics are anti-doping education, list of prohibited substances and legislation against doping behavior. This program runs with 36 to 42 hours (courses and seminars) and covers also a wide range of sport topics: match fixing, harassment, good governance in sport organizations, and abuse. This course is included in the curriculum of the Master Programs offered by the main faculties of physical education and sports.

The Sports Law program is offered at postgraduate level. The course has the status of postgraduate training and professional development and ends with an assimilated professional competence certification exam. Upon graduating from the course, a certificate of professional competence certification is issued.

\section{CONCLUSIONS}

Education for ethics and integrity has undergone transformations and new forms of implementation in training and non-formal environments in recent years, boosted mainly by Romania's accession to a range of programmatic documents in the field, reflecting European policies in sports ethics, such as anti-doping education. Other sport irregularities are mainly addressed through national programming documents and through local and national educational measures (match fixing, illegal bets, corruption and money laundering). They are important prerequisites for the accession of Romania to the treaties of the Council of Europe in the field of sport.

From the courses offered in non-formal education environments, represented by sport authorities (NADA, ROSC), as well as by organizations implementing EC-funded projects 
through Erasmus Plus Sport, to competence classes for the Doping Control Officer, the educational community in Romania is increasing its contribution to strengthening clean sports.

A significant contribution pertains to faculties, through sport education programs that, regardless of the level provided - master or postgraduate - complement the profile of specialists in the field with the specific skills to prevent, identify and report misconducting behaviors in the sport field.

In Romania, education for ethics and integrity in sport is carried out by sport institutions and by institutions responsible for training coaches. The analysis of educational offers highlights the fact that they are designed for both athletes and coaches and other categories of specialists.

We believe that Romania still has a long way to go to be in line with the European policies in the field of education for ethics and integrity in sport. This approach should be supported by administrative organizations (Ministry of Sport, Romanian Anti-Doping Agency), as well as institutions with attributions in the field of training specialists (faculties, coach schools).

\section{Acknowledgement}

The paper was realized within the Erasmus Plus Project Development of a Course to teach Coaches Sport Integrity (2017-3344/001-001) and was presented at the IX International Scientific Congress "Sport, People and Health", organized between 25th - 27th of April 2019, at Saint Petersburg (Russian Federation), by the International Social Organization for the Promotion of Science and Sports "Sport, People and Health".

\section{BIBLIOGRAPHY:}

[1] Agentia Nationala Antidoping, Strategia Nationala Andidoping (2018 - 2022).

[2] Agnew, D., Henderson, P. \& Woods, C. (2011). Ethics, Integrity and Well-Being in Elite Sport: A Systematic Review. The Sport Journal, 20. (Retrieved from http://thesportjournal.org/article/ethicsintegrity-and-well-being-in-elite-sport-a-systematic-review/).

[3] Carpanter, K. (2012). Match-Fixing - The Biggest Threat to Sport in the 21st Century? Sweet \& Maxwell's International Sports Law Review, I.S.L.R., Issue 2.

[4] Cleret, L., McNamee, M. \& Page, S. (2015). Sports Integrity' Needs Sports Ethics (and Sports Philosophers and Sports Ethicists Too). Sport, Ethics and Philosophy, 9(1), 1-5.

[5] Grigore, V., Stanescu, M. \& Stoicescu, M. (2018). Promoting Ethics and Integrity in Sport: the Romanian Experience in Whistleblowing. Revista Romaneasca pentru Educatie Multidimensionala, $10(1), 84-92$.

[6] http://www.anad.gov.ro/pdf/legea-104-2008-republicata2011.pdf.

[7] http://www.dreptonline.ro/legislatie/strategia_nationala_antidoping_2007_2012.phplz.

[8] https://sportwhistle.eu/.

[9] Ministers of Physical Education and Sport - MINEPS (2013). Declaration of Berlin. United Nations Education Scientific and Cultural Organization. Available at http://unesdoc.unesco.org/images/0022/ 002211/221114e.pdf (accessed 20 February 2019). 